\title{
Conciencia moderna y experiencia de extrañamiento. Los vértigos de Antoine Roquentin
}

\author{
Modern consciousness \\ and experience of estrangement. \\ The vertigo of Antoine Roquentin
}

\author{
LUIS PUELLES ROMERO \\ Universidad de Málaga
}

Recibido: 16/02/19 Aceptado: 21/02/2019

\begin{abstract}
RESUMEN
A partir de la Melancolía de Lucas Cranach de 1532, se indaga el linaje cartesiano de los vértigos de incertidumbre que sufre Antoine Roquentin, el protagonista de La náusea satreana. Se aborda en estas páginas cierto síndrome consistente en la dificultad de discernimiento entre cuanto sucede fuera de la conciencia y cuanto no es más que representación mental, para sostener que es esta ambigüedad la condición de posibilidad de la conciencia moderna, la de una conciencia sostenida en su misma contingencia.
\end{abstract}

PALABRAS CLAVE

CONCIENCIA, DESCARTES, SARTRE, EXTRAÑAMIENTO.

\begin{abstract}
Beginning with the Melancholy of Lucas Cranach of 1532, we investigate about the Cartesian lineage of the vertigo of uncertainty that Antoine Roquentin suffers, the protagonist of Sartre's Nausea. A certain syndrome is addressed in these pages, consisting in the difficulty of discernment between what happens outside the conscience and what is not more than mental represen-
\end{abstract}

(C) Contrastes. Revista Internacional de Filosofía, vol. XXIV-N²2 (2019), pp. 81-95. ISSN: 1136-4076 Departamento de Filosofía, Universidad de Málaga, Facultad de Filosofía y Letras Campus de Teatinos, E-29071 Málaga (España) 
tation, to sustain that this ambiguity is the condition of possibility of the modern consciousness, that of a sustained consciousness in its very contingency.

KEY WORDS

CONSCIOUSNESS; DESCARTES; SARTRE; ESTRANGEMENT

Ya no podía soportar que las cosas

estuvieran tan cerca.

J.-P. Sartre, La náusea

Desearía Comenzar esta indagación acerca del linaje que nos conduce hacia los vértigos sucedidos a Antoine Roquentin compartiendo con el lector la visión de una pintura de Lucas Cranach, su Melaconlía de 1532, perteneciente al Museo de Colmar. De ella, un detalle puede darnos indicio y génesis de lo que nos ocupará en el transcurso de estas páginas. En la parte superior derecha de esta extraña composición nos encontramos con la representación de una ventana cuya demarcación entre lo externo y lo interno no queda suficientemente reconocible; tampoco parece posible identificar con claridad cómo se integra en el espacio de la habitación la escena del fondo, en la que un putto se balancea sin que consigamos situar el punto de sujeción.

Este asunto de la indefinición entre las esferas de la mera representación mental y las existencias de objetividad contrastable, presentado de forma germinal en esta pintura de Cranach, tiene sin duda una muestra culminante en la primera narración novelística de Sartre, La nausée, a la que el propio autor habiera querido dar el título de Melancholia, además de ilustrar la primera edición de 1938 con el conocido grabado de Durero fechado en $1514 .{ }^{1}$ La idoneidad de aludir a esta escena del artista renacentista viene dada por ser este escrito sartriano un ejercicio alegórico de reflexión sobre el concepto de contingencia -la de lo humano condenado a la invención de sus propias verdades-: los instrumentos desplegados alrededor del ángel saturniano vienen a proveernos de las significaciones objetivas con las que afrontar la orfandad metafísica creciente de la Europa humanista. ${ }^{2}$

1 Fue el propio Gaston Gallimard quien decidió el título con el que conocemos esta novela desde su primera edición en 1938. A partir de 1990 un fragmento del grabado de Durero ilustra la portada de la colección Folio.

2 Las primeras páginas de esta narración que con dificultad se presta a ser llamada «novela» recibieron en 1931 el título provisional de Factum sur la contingence. Este asunto venía interesando Sartre desde 1926, cuando compuso un Chant de la contingence. 
Sin embargo, para lo que aquí habrá de interesarnos, desearía privilegiar la versión debida a Cranach, porque lo que transita entre el «amorcillo» columpiándose y las sucesivas inquietudes anotadas por Roquentin en las páginas de su diario es precisamente esta ilocalizabilidad del motivo desasosegante: la dificultad para poder advertir si debe constituirse como un problema externo, constatable y compartido en el plano de la realidad objetiva, o, al contrario, y con otros estremecimientos en consecuencia, tiene que ver con la interioridad alterada del sujeto. El trance de indistinción entre ambos planos está expresado por Roquentin de este modo: «Lo curioso es que no estoy en absoluto dispuesto a creerme loco; incluso veo con evidencia que no lo estoy: todos estos cambios conciernen a los objetos. Al menos quisiera estar seguro de esto» (Sartre, J.-P., 1999, p. 14); o así:

Se ha producido, pues, un cambio durante estas últimas semanas. ¿Pero dónde? Es un cambio abstracto que no se apoya sobre nada. ¿Soy yo quien ha cambiado? Si no soy yo, entonces es esta habitación, esta ciudad, esta naturaleza; es necesario elegir (Ibidem, p. 18).

Es necesario elegir... Será la constatación de cómo actúa esta indeterminación, en la forma de ciertos extravíos, a través de la propia definición moderna de la conciencia subjetiva, la que habrá de ocuparnos en nuestro esfuerzo por alcanzar alguna dilucidación del pavor que sacude al personaje sartriano. Con esta intención, y ya que -como no puede ser de otro modohemos comenzado situándonos en el contexto marcado por el Renacimiento, podrían ser algunos de los presupuestos aportados por Heidegger en su escrito sobre La época de la imagen del mundo (una conferencia, por cierto, dictada en Friburgo el mismo año de publicación de La náusea: 1938) los que den su primera definición a nuestro trayecto, el cual se sucederá como una especie de genealogía de la conciencia extrañada que distara desde los excesos del cogito cartesiano hasta estas instrospecciones de Antoine Roquentin. Entre ambos términos, dos consideraciones tomadas de Kant, el escrito de Nietzsche Sobre verdad y mentira en sentido extramoral (redactado al dictado en 1873) y un aspecto concreto del conocido ensayo de Freud dedicado a Das Unheimliche (1919) son los episodios con los que compondremos este síndrome de la indefinición indisoluble entre cuanto corresponde a la objetividad -a pesar de sus anomalías e irregularidades-y cuanto es asignable a una subjetividad presa de presencias fantasmagóricas. ${ }^{3}$

3 En este mismo recorrido, además de los mencionados enclaves, bien se podría atender a otras muestras de estos mismos vértigos: El Horla de Maupassant, la Carta de Lord Chandos de Hofmannsthal y el Monsieur Teste de Paul Válery son ocasiones privilegiadas en las que observar cómo se comporta la conciencia abismática. 
Empecemos por tanto reparando en la interpretación que hace Heidegger acerca de la doble instauración, en términos ontológico y cognoscitivo, mediante la cual se ha hecho posible el desenvolvimiento de la episteme vigente entre el Renacimiento y la crisis de la representación advenida en las últimas décadas del siglo XIX: la constitución identificatoria del hombre como subjectum y, en reciprocidad con ella, del mundo como representación. Obteniendo la capacidad de «poner ante sí y traer hacia sí», el sujeto moderno gana la posición y la perspectiva de erigir frente a él, y a él mismo orientado, el mundo objetualizado y progresivamente objetivado como representación. Así, es a condición de abrir la distancia - protectora- con las cosas como éstas, perdiendo ante-para nosotros la inmediatez indómita de su presencia, se prestan a ser entendidas como representaciones, esto es, susceptibles de recibir significación convencional.

Sujeto y objeto se sostienen así en el equilibrio precario que los tensa a través de una distancia instauradora: es ella la que da al sujeto su posición de privilegio en el entendimiento de la representación. Sujeto y objeto se hacen relativos entre sí -siendo entonces subjetividad y objetividad- a través de la distancia tendida sobre los vértigos de la contingencia, la arbitrariedad antropomórfica de los signos, la revisión permanente de todas las certezas. Como veremos a propósito de Nietzsche, y ya desde su umbral renacentista, el conocimiento que se debe a la representación pende como un puente sobre el vacío.

De acuerdo con esto, podría ocurrir que el sujeto protegido mediante la distancia padezca eventualmente la desestabilización de su posición. Como si la distancia se cerrara y, sin esperarlo, quedásemos aturdidos por la presencia de (las) cosas que creíamos suficientemente alejadas como para poder ser entendidas o reconocidas a través del entendimiento conformante de la representación. Como en el cuadro de Magritte Les objets familiers (1928), las cosas nos asaltarían los ojos. Este vértigo esencial a la conciencia permanecerá irreprimible a lo largo de los siglos modernos, comportándose como el reverso demencial de la episteme de la representación.

Es Descartes quien se presta - tentativamente- a los vértigos de estos reversos dánsose a sí dos condiciones "metodológicas": apartándose y mirándose. Ambas actitudes, rigurosamente vigiladas, constituyen la conformación del mundo como dominio cognoscitivo objetualizado. También el sujeto alcanza así la capacidad reflexiva de hacerse objeto para sí: observándose, perdiendo la inmediatez de la mera actuación para obtener a cambio la conciencia alejada de las presencias. El examen cartesiano, tan meticuloso como excesivo en su exigencia ilimitada de introspección, es él mismo extrañante respecto de las relaciones que hacen del sujeto una instancia de mera gestión mundana. Descartes se para a mirarse: se mira demasiado -como lo hace el desdichado protagonista de Le Horla, tanto como Monsieur Teste y Antoine Roquentin-, hasta el punto de quedar apartado de todo y de todos. El abocamiento cartesiano 
a hacernos con la representación del mundo objetualizándolo, suspendiéndolo, a ganar sobre él nuestro dominio cognoscitivo a través del cálculo y la medida, la geometría y las clasificaciones, tiene por reverso melancólico la pérdida de la presencia.

Podríamos remontarnos a los velamientos de la evidencia propiciados por Descartes en sus Meditaciones metafísicas (1641) para encontrarnos con un primer episodio de esta confusión entre lo que existe fuera y cuanto pudiera corresponder a la esfera proyectiva de la subjetividad: la introspección cartesiana atisba la posibilidad -orquestada por el genio maligno, una figura retórica con la que poder radicalizar la duda- de que sólo pudiera haber representaciones; una posibilidad, agónica, que nunca se volverá certidumbre o evidencia. Así, hacia el final estremecedor de la Primera Meditación, el autor lleva al extremo su sospecha:

Así pues, supondré que hay, no un verdadero Dios -que es fuente suprema de verdad-, sino cierto genio maligno, no menos artero y engañador que poderoso, el cual ha empleado toda su industria en engañarme. Pensaré que el cielo, el aire, la tierra, los colores, las figuras, los sonidos y todas las cosas exteriores no son sino ilusiones y ensueños, de los que él se sirve para atrapar mi credulidad. Yo me consideraré a mí mismo como sin manos, sin ojos, sin carne, sin sangre, sin sentido alguno, pero creyendo falsamente que tengo todo eso (Descartes, R., 1953, p. 272).

El filósofo escenifica con estas palabras la prueba de enajenarse de la reconocibilidad del mundo, cayendo en la tentación de imaginarlo como siendo una ficción, la fantasía verosímil creada por un gran soñador engañador. Descartes es el primero en dejarse tentar por la posibilidad abismática-que no llega a culminarse en términos de demostración- de que el mundo no sea más que una ilusión, la trama de nuestras propias representaciones; esto es, una ficción o invención capaz de hacernos creer que existe sin nosotros. ${ }^{4}$ Las Meditaciones metafísicas inauguran las mayores inquietudes de la conciencia, las que conciernen a la oscilación indeterminada -como aquel columpio pintado por Cranach- entre lo procedente de fuera y lo debido a la capacidad proyectiva de la subjetividad:

4 Corinne Enaudeau lo expresa de esta manera: «No sólo no alcanzamos la esencia de lo real, sino que tampoco tenemos la seguridad de que exista. Las Meditaciones son el relato de la lucha metódica por atribuir a las cosas algo más que un ser de razón: una existencia efectiva, independiente del espíritu que la piensa; son una lucha, pues, por dar cuerpo a fantasmas, si no carentes de consistencia, con una existencia sólo representativa» (Enaudeau, C., 1999, p. 52). 
[...] que yo tenga la facultad de concebir lo que en general llamamos una cosa, o una verdad, o un pensamiento, me parece, por otra parte, que procede únicamente de mi propia naturaleza; pero si oigo ahora un ruido, si veo el sol, si siento calor, he juzgado hasta el presente que estos sentimientos procedían de cosas existentes fuera de mí; y, en fin, me parece que las sirenas, los hipogrifos y todas las demás quimeras parecidas son ficciones e invenciones de mi espíritu. Pero también podría persuadirme de que todas estas ideas son del género de las que llamo extrañas, y que vienen de fuera, o bien que todas han nacido conmigo, que todas han sido hechas por mí; puesto que todavía no he descubierto su verdadero origen. Y lo que principalmente debo hacer, en este punto, es considerar, respecto de aquellas que me parecen proceder de ciertos objetos que están fuera de mí, cuáles son las razones que me obligan a creerlas semejantes a esos objetos (Descartes, R., op. cit., p. 287).

No nos queda más que fijar la separación entre ambos planos, y asignar a la conciencia la vigilancia de su mantenimiento. El rigor del clasicismo se da justamente este cometido: el de mantener dicha separación entre la razón y sus márgenes, preservando así la claridad del signo, la expulsión de las ambigüedades, la racionalización universal en el esfuerzo por poner orden en lo real.

Situados en las últimas décadas del siglo XVIII, es Kant, liberado de los ingenuismos racionalistas, quien, avanzando a partir de donde Descartes se detuvo, nos retiene a propósito de esta dificultad creciente de la conciencia para mantener la linde entre presencias y representaciones. En su Antropología en sentido pragmático (1798), nos traslada una advertencia acerca de la potencia alucinatoria propia de la acción imaginante:

La ilusión causada por la fuerza de la imaginación humana va con frecuencia tan lejos que el hombre cree ver y tocar fuera de sí lo que sólo tiene en su cabeza. De aquí el vértigo que acomete al que mira un abismo, aun cuando tenga en torno suyo una superficie suficientemente ancha para no caer o incluso se halle tras una sólida barandilla (Kant, I., 2004, p.34).

Efectivamente, en los pocos años que transcurren entre los trabajos de Kant y la obra mayor de Schopenhauer crecen las sospechas relativas a la índole alucinatoria de las representaciones, contribuyendo esto al incremento de la indeterminación entre fuera y dentro. Vayamos con alguna calma y acudamos primero a la Crítica del Juicio (1790), para atender a una cuestión precisa y bien conocida. Se encuentra al inicio, en el $\S 2$, donde se trata el asunto del desinterés, medular de esta obra principal:

[...] cuando se pregunta si algo es bello no se desea saber si a nosotros o a cualquier otro nos va o nos podría ir algo en la existencia de la cosa, sino que se pregunta 
cómo la enjuiciamos en la mera contemplación (intuición o reflexión) [...] Sólo se desea saber si la mera representación del objeto en mí está acompañada de satisfacción, totalmente al margen de la existencia del objeto de esta representación (Kant, I., 2003, pp. 152-3).

Se postula así la impertinencia, para el juicio estético, de que deba ser requerida la existencia empírica -comprobatoria-de lo referido en la representación. Simplemente resulta irrelevante. En términos de juicio estético, deberá postularse el principio de contingencia en lo que concierne a la «existencia real» de tales representaciones fenoménicas. La representación pudiera no remitir sino a alguna irrealidad (si bien esto también sería indiferente). Como el propio Kant advierte, no cabe para la representación mayor soberanía que la de apuntar a lo inexistente, quedando libre de tener que significar con fidelidad a lo real.

De este modo, ya desde el principio mismo de la Crítica del juicio -tan neoclásica en sus definiciones como pre-romántica en sus implicaciones-, se nos sugiere que la representación puede poseer la ontología del fantasma, puede serlo de lo inexistente; su identidad se sitúa entre la mostración y la ilusión, entre la absolutización de la dimensión fenoménica y, con ella en su reverso, la posibilidad no sancionada, de que los fenómenos no sean más que apariciones.

Al fin y al cabo, ambas nociones, fenómeno («lo que aparece») y fantasma («aparición», pero también «visión», o «imagen engañosa»), poseen la misma procedencia griega: phaínein. Esta doble definición nos descubre la imposibilidad de discernir con precisión entre lo que de la realidad se aparece, o manifiesta, a lo que llamaríamos «fenómeno», y esa otra dimensión del aparecer, la propia del fantasma, que carece de remisión a lo real. Afirmar lo fenoménico -y así lo hace Kant- nos aboca hacia las visiones y los espectros, fantasmas cuya índole ontológica no trasciende a la mera aparición. ${ }^{5}$

Como Schopenhauer, en su Ensayo sobre la visión de espectros y lo que se relaciona con ella, De Chirico (tan influido por este mismo escrito perteneciente a los Parerga y Paralipómena), los surrealistas y el Sartre de La náusea (también Robbe-Grillet y Alain Resnais en El último año en Marienbad) ex-

5 En este sentido, puede sernos esclarecedor acudir a la distinción, fijada por Platón en el Sofista (235 d-237 a), entre las imágenes producidas por la técnica figurativa o imitativa (tékhnē eikastiké), copias sin otro cometido que el de reproducir sus modelos con obediente e inequívoca fidelidad, y aquellas otras, las imágenes-simulaciones (debidas a la tékhnē phantastikê), que «sólo aparentan parecerse, sin parecerse realmente» (236 b); entre las imágenes que se cumplen propiciando que por ellas se alcance el modelo y las apariencias afanadas en quedar ellas mismas antepuestas, imponiéndose como presencias engañosas. Estas segundas, si bien se cubren del (con el) parecido, no son indicativas de nada que sea real. Fingen parecerse a lo que no es. No tienen otra dimensión que la de ser apariencias o fantasmas. Parecen sin llegar a ser (236 d). Puede verse a este respecto el artículo de Gilles Deleuze «Renverser le platonisme» (Revue de Métaphysique et de morale, 1967; como apéndice en Logique du sens. Paris: Minuit, 1969). 
plorarán esta ambigüedad constitutiva entre lo real del fenómeno y lo irreal del fantasma, entre las rarezas del mundo objetivo y los delirios de la subjetividad.

Sin abandonar todavía a Kant, quisiera referirme a otro aspecto. Es en su Antropología donde nos encontramos con la diferencia entre los dos «vicios de la imaginación», son estos:

Los vicios de la imaginación son: que sus ficciones sean ya simplemente desenfrenadas, ya absolutamente desarregladas (effrenis aut perversa). Este último yerro es el peor. Las primeras ficciones pudieran, en efecto, encontrar su puesto en un mundo posible (de la fábula); estas últimas en ninguno, porque se contradicen. [...] la desarreglada se acerca a la demencia, en que la fantasía juega íntegramente con el hombre y el desgraciado no tiene en absoluto en su poder el curso de sus representaciones (Kant, I.: 2004, p. 94).

Las primeras, las ficciones desenfrenadas, aun siendo excesivas y en todo caso inveraces desde el punto de vista de cuanto rige en el mundo ordinario que tenemos por real (están, efectivamente, fuera de cuanto supone mantenerse «contenidas» en la realidad de permanencia habitual), pueden sin embargo acomodarse y dotarse de suficiente inteligibilidad bajo las condiciones postuladas por una fábula. La ficción genera - es- una propuesta de mundo, o sea, de orden cohesionado y coherente que, aunque de naturaleza estrictamente imaginaria, no está falto de una consistente lógica interior. La ficción es adversa al sinsentido, al absurdo, a la contradicción (entendida esta como vulneración del principio de identidad); crea un mundo que debe hacerse creíble, o sea, suficientemente sostenido y plausible, capaz de explicarse a sí mismo haciéndose entender con sus propios medios. En ese mundo, las imágenes «desenfrenadas» se prestan a ser acogidas, de un modo u otro, en un orden coherente e imaginario.

Sin embargo, es el segundo "vicio» el que nos ayudará a avanzar en la definición de la condición de extravío que nos parece esencial a las imágenes objetuales que cercan a Antoine Roquentin. Kant las llama desarregladas. No son simplemente abusivas o «exageradas», lo que las haría susceptibles del pacto de la ficción, sino que carecen de mundo -o se han quedado sin mundo-por el que «regularse». En tal caso, su modo de ser es apareciéndose como excepción o irregularidad en unos términos precisos: desajustándose o desencajándose («hay algo que no encaja», solemos decir en tales casos) del mundo que teníamos previsto. Tales imágenes quedan desacogidas por la comprensión que hubiera de integrarlas en la trama de los signos (con los que ordenar el mundo); mostrándosenos (como) en estado de suspensión.

Cabría decir que, para deshumanizarse, las imágenes que turban a Roquentin deben acometer su propia des-mundaneización. Como una punzada, como un estremecimiento sucedido en los confines ganados por la mismidad, es $l o$ otro anidado en la identidad lo que se nos revela, provocándose de este modo la 
parálisis, el shock que sólo se produce en la crisis de la evidencia, cuando no se trata ya de asimilar platónicamente lo desconocido a lo conocido, de entender lo extraño y traerlo a lo reconocible, sino de quedar alterados sin «evadirnos» de la identidad. Es nuestra relación de dominio con el mundo de las evidencias la que queda aquí desestabilizada en sus mismas posiciones protectoras de la subjetividad (de la conciencia) y a distancia del mundo objetual y objetivado.

A la vez que cruzamos la linde hacia el siglo XIX constatamos cómo la vivencia estética se nutre de un factor decisivo: el viejo sujeto perspectivista y cartesiano, dedicado afanosamente a la objetualización de lo inmediato, lo familiar, lo habitual, lo íntimo, se encuentra de repente arrebatado de la distancia protectora, constitutiva del propio sujeto, para quedar él mismo relegado a ser objeto de la acción de atrapamiento que la obra de arte dirige hacia él y en no pocas ocasiones directamente contra él: contra su facultad de entendimiento, contra su posición de privilegio cognoscitivo, contra su necesidad de fijar representaciones para evitar con ellas las turbulencias de la presencia opaca al sentido, esto es, extrañándolo de lo que venía siendo y creyendo ser en términos de conciencia vigilante del mundo y de sí.

El sujeto protegido en su conciencia inalcanzable se halla ahora rendido a una experiencia que lo expulsa de la relación cognoscitiva de reconocibilidad. Ha perdido la capacidad de entender lo que siente (lo que se le hace sentir); y es por esto por lo que su vivencia es de sobrecogimiento. Es efectivamente en este contexto de configuración de una subjetividad debida a la suscitación de experiencias más o menos sobrecogedoras cuando acontecen los primeros compases del efecto de extrañamiento que definirá a buena parte de recursos empleados por las artes plásticas y literarias durante la primera mitad del siglo XX y que tendrá en La náusea una de sus culminaciones ejemplares.

Las correspondencias entre las poéticas de las revelaciones y el efecto de extrañamiento que en ellas se incuba tienen sus primeros indicios en la crisis de la evidencia diagnosticada por Nietzsche en su escrito de 1873 (publicado en 1903). Lo primero que debemos convenir antes de entrar en estas páginas del joven Nietzsche es que es inherente a la evidencia comportarse como si se sostuviera sobre sí misma - de ahí su valor para las fundamentaciones metafísicas y las verdades sagradas- y no, al contrario, en las operaciones lógicas, ontológicas y artísticas que tramamos con signos inciertos. Frente a esto, Nietzsche nos dice que la creencia en las verdades radica en el olvido de que no son más que ilusiones debidas a nuestra capacidad de concitación del sentido: «Solamente mediante el olvido puede el hombre alguna vez llegar a imaginarse que está en posesión de una "verdad" [...]» (Nietzsche, F., 2012, p. 25). La actividad de la fantasía fundadora de la verdad debe mantenerse como un Sísifo incansable: 
Ese impulso hacia la construcción de metáforas, ese impulso fundamental del hombre del que no se puede prescindir ni un solo instante, pues si así se hiciese se prescindiría del hombre mismo, no queda en verdad sujeto y apenas si domado por el hecho de que con sus evanescentes productos, los conceptos, resulta construido un nuevo mundo regular y rígido que le sirve de fortaleza (Ibídem, p. 34).

Salir de la ilusión - de la que Nietzsche nos expulsa- es caer en la constatación desencantada de que sólo cabe conocer lo que se pudo crear: «todo el material sobre el que, y a partir del cual, trabaja y construye el hombre de la verdad, el investigador, el filósofo, procede, si no de las nubes, en ningún caso de la esencia de las cosas» (Ibídem, p. 27). ${ }^{6}$

Si con Descartes se inaugura la modernidad en la forma de un apartamiento o retiro de la evidencia cognoscitiva, hasta el punto de llegar a suponerse -sin llegar a afirmarse- que el mundo no sea más que una representación, con Nietzsche nos encontramos ante el extrañamiento de la inmediatez lingüística. Llevando al extremo la tentación cartesiana, Nietzsche se pregunta: «¿Concuerdan las designaciones y las cosas? ¿Es el lenguaje la expresión adecuada de todas las realidades?» ( Nietzsche, F.: op. cit., p. 27). De este modo se instaura la crisis de la designación que Nietzsche hace arrancar de la inefabilidad de las sensaciones. En tal situación, el lenguaje se limita a ser una trama de metáforas dedicada a la ilusión de hacernos creer que en ella se está nombrando el mundo. Hacia el final de su escrito, decreta Nietzsche la conclusión esperada:

Entre dos esferas absolutamente distintas, como lo son el sujeto y el objeto, no hay ninguna causalidad, ninguna exactitud, ninguna expresión, sino, a lo sumo, conducta estética, quiero decir: un extrapolar alusivo, un traducir balbuciente a un lenguaje completamente extraño (Ibídem, p. 31).

¿Qué significa esta inadecuación del mundo y las palabras, esta extrañeza recíproca? La sospecha en la arbitrariedad y contingencia de la función lingüística designativa implicará no sólo la aceptación de un «abismo» entre ambas esferas que hace de todo conocimiento que se crea verdadero una simple ilusión presa de la mentira, sino que da al traste con la función legislativa y ordenadora del lenguaje como agente inductor de posibles sentidos apropiados al mundo.

Cabe admirar al hombre en este caso como poderoso genio constructor que acierta a levantar sobre cimientos inestables y, por así decirlo, sobre agua en movimiento

6 El propio Kant advirtió en su Crítica de la razón pura esta exigencia cognoscitiva que nos vuelca hacia los vértigos de la subjetividad: «Somos, pues, nosotros mismos los que introducimos el orden y la regularidad de los fenómenos que llamamos naturaleza. No podríamos descubrir ninguna de las dos cosas si no hubieran sido depositadas allí desde el principio, bien sea por nosotros mismos, bien sea por la naturaleza de nuestra mente» (Kant, I.: op .cit., p. 148). 
una catedral de conceptos infinitamente compleja: ciertamente, para encontrar apoyo en tales cimientos debe tratarse de un edificio hecho como de telarañas, suficientemente liviano para ser transportado por las olas, suficientemente firme para no desintegrarse ante cualquier soplo de viento (Ibídem, p. 30).

Se trataría, entonces, de crear puentes inestables, provisionales, sustituibles, $y$, como tales, estrictamente sostenidos en la suspensión. La enajenación de las cosas, la pérdida de la posición de dominio lingüístico -y humanizante-que creímos perenne, constituirá el motivo central del sentimiento de extrañamiento que las artes y la literatura de las vanguardias explorarán sin descanso. ${ }^{7}$

Vayamos al conocido artículo de Freud aparecido en la revista Imago en 1919, Das Unheimliche, para concentrarnos en un solo detalle de su argumentación. A la vez que circunscribe la indagación estética al análisis de la sensibilidad, Freud obvia la diferencia entre la experiencia provocada por los objetos del mundo (la que podríamos llamar «la vivencia mundana»), al afectarnos estos de un modo que no requiere de la «actitud estética», y la experiencia producida por la representación artística (ficcional o no), siendo esta segunda la que sí concentra y conduce a un modo de dejarse afectar (a distancia) que sería el específicamente estético. Parece que Freud atendiera especialmente a la dimensión psicológica de esta «cualidad sensitiva», a la vez que no entra en la consideración de la autonomía estética respecto de la experiencia ordinaria. Esto, que puede pasar por anecdótico, nos revela un aspecto específico del sentimiento de desacogimiento: que nos impide situarnos en el espacio (protector) de la representación; con el sentimiento de lo perturbador-cotidiano quedamos arrojados inesperadamente en la pérdida de esta distancia. El vértigo (del sentido de realidad) con que nos afecta lo inhóspito no es otro que el de esta desestabilización de la distancia. Preso así del espanto, el sujeto asiste a las alteraciones irreconocibles de la presencia que venía siendo familiar: el propio sujeto pierde su propiedad sobre el objeto, quedando él mismo objetualizado.

El escrito de Freud nos centra en la constatación de esta incertidumbre de localización entre lo exterior y lo interior, entre lo subjetivo y lo objetivo. Refiriéndose al relato de E.T.A. Hoffmann «El hombre de arena», Freud declara:

Es verdad que el poeta provoca en nosotros al principio una especie de incertidumbre, al no dejarnos adivinar -seguramente con intención-si se propone conducirnos al mundo real o a un mundo fantástico, producto de su arbitrio. [...]

7 La Carta de Lord Chandos, escrita por Hugo von Hofmannsthal en 1901, es una muestra de la pérdida de la reconocibilidad que habrá de minar el siglo XX de incertidumbres. Lord Chandos está tomado por el sentimiento de desnaturalización del lenguaje, por el que éste, al dejar de ser discriminatorio de los objetos en sus significados, evidencia la ininteligibilidad radical -o insignificancia- de las cosas concretas. 
Pero en el transcurso del cuento de Hoffmann se disipa esa duda y nos damos cuenta de que el poeta quiere que nos miremos a nosotros mismos a través del diabólico anteojo del óptico, o que quizá también él mismo en persona haya mirado por uno de esos instrumentos (Freud, S., 1979, p. 21).

No es casual que haya sido Freud quien ha traído al siglo XX la mayor tematización de la extrañeza de lo familiar. La experiencia de lo inquietante, cuando se produce enrarecimiento o alteración en relación con los objetos cotidianos, no puede limitarse a una experiencia que por parte del que la siente se circunscriba sin más a la esfera de la subjetividad o de una cierta sugestión inducida; en tal caso no advendría la punzada de enajenación, de alteración del sentido que es propia a este sentimiento. El que experimenta lo siniestro debe creer que eso que le pasa está producido por un objeto externo objetivamente inquietante o terrorífico.

Al quedar expulsados del espacio de la representación, nos vemos en la imposibilidad de determinar cuánto corresponde, o es atribuible, a la subjetividad (que pudiera estar alterada) y, por el contrario, cuánto pertenece al ámbito de lo objetivo (y, por lo tanto, es susceptible de ser contrastado por medios demostrativos de su particular existencia y, lo que no es menos apaciguador, «compartido» por otros alterados por lo mismo que yo). El extrañamiento supone, por tanto, la confusión entre dos términos que debieran quedar nítidamente confrontados: el sujeto y el objeto, y el vértigo advenido a una conciencia extraviada, desposeía de sí misma. Al fin, la conciencia no es más que una posición rígidamente sostenida.

Donde se aprecia con toda nitidez esta ilusión de objetivismo es en las palabras de Antoine Roquentin (tan próximo al Lord Chandos de Hofmannsthal): «Lo curioso es que no estoy nada dispuesto a creerme loco, veo con evidencia que no lo estoy: todos estos cambios conciernen a los objetos. Al menos quisiera estar seguro de esto» (Sartre, J.-P. : op. cit., p. 14). Y unas páginas más adelante se lee:

En mis manos, por ejemplo, hay algo nuevo, una cierta manera de coger la pipa o el tenedor. $\mathrm{O}$ bien es el tenedor el que tiene, ahora, una cierta manera de hacerse coger, no sé. Hace un instante, cuando iba a entrar en mi cuarto, me detuve en seco, al sentir en la mano un objeto frío que retenía mi atención con una especie de personalidad. Abrí la mano, miré: era simplemente el pomo de la puerta (Ibídem, pp. 17-8).

Parece que los objetos se volvieran irreconocibles, «extraños», sin perder por ello un ápice de realidad, sin lanzarse a los vuelos evasivos de la fantasía. Es ahí donde se sitúa el surrealismo. No es un mentalismo y tampoco un irrealismo, aunque quizá sea posible pensar en un cierto efecto de irrealidad 
(de irrealización de lo real), el cual consiste en «sentir» el alejamiento de lo real (lo real como lejano) a condición de que este alejamiento no debilite la certeza-evidencia de que es real.

Todorov se ha detenido en esta oscilación inherente a la potencia del fantasma:

En un mundo que es seguramente el nuestro, el que conocemos, un mundo sin demonios, ni sílfides, ni vampiros, se da un acontecimiento que no puede explicarse con las leyes de ese mundo que nos es familiar. Quien percibe tal acontecimiento debe optar por una de las dos soluciones posibles: o bien se trata de una ilusión de los sentidos, de un producto de la imaginación, y, en tal caso, las leyes del mundo subsisten tal y como son; o bien el acontecimiento ha sucedido realmente, es parte integrante de la realidad, y, entonces, esa realidad está regida por leyes que nos son desconocidas [...] Lo fantástico ocupa el lapso de tiempo de esta vacilación; apenas se ha optado por una u otra solución, se abandona la dimensión de lo fantástico para entrar en otra de un género semejante, la de lo extraño o la de lo maravilloso (Todorov, T., 1970, p. 29).

Todorov incide en la diferencia entre lo extraño y lo entrañante. En el primero de estos dos casos, no estamos más que ante lo todavía desconocido, o ante aquello que postulamos en la forma de los mundos maravillosos con su capacidad de encantamiento. Los géneros de la ficción, pero no menos los géneros de lo fantástico sobrenatural, nos instalan en un mundo. El extrañamiento actúa haciéndonos perder las evidencias que habíamos creído ganar a propósito de lo que considerábamos como "suficientemente" conocido.

En los últimos pasos de estas páginas querría detenerme en cómo actúa de forma concreta a lo largo de La náusea la imposición de los cosas sobre la conciencia, de la dificultad padecida por Roquentin para mantenerse protegido por los hábitos y las representaciones. En este sentido, hallamos a lo largo de la narración un motivo permanente: la inmediatez desestabilizante del contacto sensorial. Como pudiéramos encontrar en la Carta de Lord Chandos, Sartre rompe la distancia protectora de la que nos provee la representación para someter a Roquentin a una vivencia «histérica» en la que son las cosas las que se imponen a la subjetividad.

Reparemos en cómo se comporta la mirada con la que mantener la reconocibilidad de los objetos para atender a continuación a la escena del castaño, en la que, sin palabras, sin lenguaje, Roquentin queda «en medio de las cosas»:

Mientras pudiera ver los objetos, no ocurriría nada: miraba todo lo posible el pavimento, las casas, los faroles de gas; mis ojos pasaban rápidamente de unos a otros para sorprenderlos y detenerlos en medio de sus metamorfosis. No parecían demasiado naturales, pero yo me decía con fuerza: es un 
farol de gas, es una fuente, y trataba de reducirlos a su aspecto cotidiano mediante el poder de mi mirada (Sartre, J.-P.: op. cit., pp. 103-4).

Y más abajo, cuando se inicia la crisis en el Jardín público, con la que culmina el proceso de extrañamiento que padece el protagonista, todo se acerca demasiado, y las palabras no consiguen mantener la distancia que las nombra («la palabra permanece en mis labios; se niega a posarse en la cosa»):

Las cosas se han liberado de sus nombres. Están ahí, grotescas, obstinadas, gigantescas, y parece imbécil llamarlas banquetas, o decir algo de ellas: estoy en medio de las Cosas, las innominables. Solo, sin palabras, sin defensa, las Cosas me rodean, debajo de mí, detrás de mí, sobre mí (Ibídem, p. 161).

Valgan estas líneas para observar en ellas cómo se produce en el linaje de la conciencia moderna un equilibrio precario, sostenido de forma provisional, entre el sujeto y las cosas que forman parte de lo que llamamos el mundo objetivo. El lenguaje y la mirada contribuyen con decisión a mantener la distancia por la que nos damos la ilusión de que el mundo existe sin nosotros, pudiendo ser además identificable y, en definitiva, reconocible. Es esta "separación" la que nos da alguna claridad y distinción en nuestras representaciones del mundo. En estas páginas hemos intentado recorrer el camino que se extiende entre las especulaciones de suspensión del mundo concebidas por Descartes y la demolición de las distancias relatada por Sartre a través de la subjetividad alterada de Antoine Roquentin. Entre ambos, la conciencia ha debido afrontar el reverso que acompaña a las representaciones: significar el mundo coincide con perderlo. Con ir perdiéndonos.

\section{REFERENCIAS BIBLIOGRÁFICAS}

Deleuze, G., «Renverser le platonisme» en Revue de Métaphysique et de morale, 1967; en Logique du sens, Paris, Minuit, 1969.

Descartes, R., Euvres et Lettres. Paris: Gallimard-La Pléiade, 1953.

Enaudeau, C., La paradoja de la representación. Buenos Aires: Paidós, 1999.

Freud, S., Lo siniestro. Barcelona: José J. de Olañeta, 1979.

Kant, I., Antropología en sentido pragmático. Madrid: Alianza Ed., 2004.

-_--, Crítica del discernimiento. Madrid: Antonio Machado Libros, 2003.

Nietzsche, N., Sobre verdad y mentira en sentido extramoral. Madrid: Tecnos, 2012.

Sartre, J.-P., La nausée. Paris: Gallimard (col. Folio), 1999.

Todorov, T., Introduction à la littérature fantastique. Paris: Seuil, 1970. 
Luis Puelles Romero es profesor titular de Estética y Teoría de las artes de la Universidad de Málaga.

Lineas de investigación:

Actualización contemporánea de algunas categorías estéticas de formulación característicamente moderna.

Publicaciones recientes:

Puelles, L., Mirar al que mira. Teoría estética y sujeto espectador, Abada, Madrid, 2011

—. Honoré Daumier. La risa republicana, Abada, Madrid, 2014

_- Imágenes sin mundo. Modernidad y extrañamiento, Abada, Madrid, 2017

_- Mítico Manet. Ideologías estéticas en los orígenes de la pintura moderna, Abada, Madrid, 2019

Email:1pr@uma.es 
